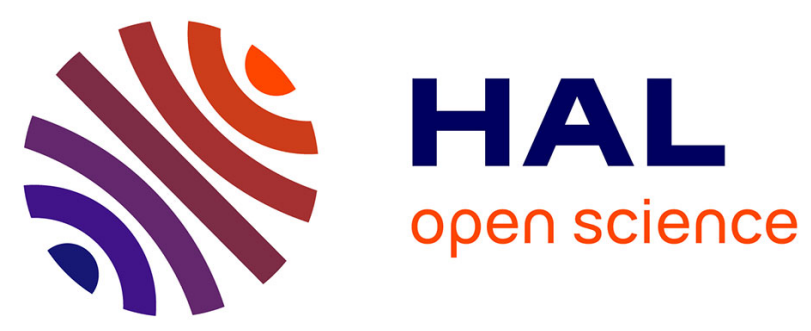

\title{
One-dimensional simulation of solute transfer in saturated-unsaturated porous media using the discontinuous finite elements method
}

E.B. Diaw, Francois Lehmann, Philippe Ackerer

\section{- To cite this version:}

E.B. Diaw, Francois Lehmann, Philippe Ackerer. One-dimensional simulation of solute transfer in saturated-unsaturated porous media using the discontinuous finite elements method. Journal of Contaminant Hydrology, 2001, 51 (3-4), pp.197-213. 10.1016/S0169-7722(01)00129-2 . hal-03200878

\section{HAL Id: hal-03200878 \\ https://hal.science/hal-03200878}

Submitted on 16 Apr 2021

HAL is a multi-disciplinary open access archive for the deposit and dissemination of scientific research documents, whether they are published or not. The documents may come from teaching and research institutions in France or abroad, or from public or private research centers.
L'archive ouverte pluridisciplinaire HAL, est destinée au dépôt et à la diffusion de documents scientifiques de niveau recherche, publiés ou non, émanant des établissements d'enseignement et de recherche français ou étrangers, des laboratoires publics ou privés. 
One-dimensional simulation of solute transfer in saturated - unsaturated porous media using the discontinuous finite elements method

DIAW E. B. ${ }^{1,2}$, LEHMANN F. ${ }^{2}$ and ACKERER PH. ${ }^{2}$

1. Université Cheikh Anta DIOP de Dakar, Ecole Supérieure Polytechnique centre de Thiès (ESP/T), département de Génie Civil, B.P A10 Thiès-Sénégal.

2. Institut de Mécanique des Fluides et des Solides, UMR 7507 ULP-CNRS, 2, rue Boussingault, 67000 StrasbourgFrance.

Corresponding author

$\mathrm{Ph}$. ACKERER

IMF2S

2 , rue Boussingault

67000 STRASBOURG

Tél: 33 (0)390 242909

Fax: 33 (0)388 614300

E-mail: ackerer@imfs.u-strasbg.fr 


\title{
One-dimensional simulation of solute transfer in saturated - unsaturated porous media using the discontinuous finite elements method
}

DIAW E. B. ${ }^{1,2}$, LEHMANN F. $^{2}$ and ACKERER PH. ${ }^{2}$

3. Université Cheikh Anta DIOP de Dakar, Ecole Supérieure Polytechnique centre de Thiès (ESP/T), département de Génie Civil, B.P A10 Thiès-Sénégal.

4. Institut de Mécanique des Fluides et des Solides, UMR 7507 ULP-CNRS, 2, rue Boussingault, 67000 StrasbourgFrance.

\begin{abstract}
A one-dimensional transport model for simulating water flow and solute transport in homogeneousheterogeneous, saturated-unsaturated porous media is presented. The model is composed of a combination of accurate numerical algorithms for solving the non linear Richards' and advectiondispersion equations (ADE). The mixed form of Richards' equation is solved using a standard finite element method (FEM) with primary variable switching. The transport equation is solved using operator splitting, with discontinuous finite elements method (DFE) for the discretization of the advective term. A slope limiting procedure for DFE avoids numerical instabilities but creates very limited numerical dispersion for high Peclet numbers. An implicit finite differences scheme (FD) is used for the dispersive term.

The unsaturated flow and transport model (Wamos-T) is applied to a variety of rigorous problems including transient flow, heterogeneous medium and abrupt variations of velocity in magnitude and direction due to time varying boundary conditions. It produces accurate and mass-conservative solutions for a very large range of grid Peclet numbers. Wamos-T model is a good and robust alternative for the simulation of mass transport in unsaturated domain.
\end{abstract}

Keywords : Unsaturated porous media ; Numerical model; Mass transport ; Discontinuous finite element ; Operator splitting. 


\section{Introduction}

Transfer of water and solutes under transient unsaturated-saturated conditions plays an important role in agriculture and environmental engineering. The unsaturated zone is prone to contamination from agriculture where many chemicals such as fertilizers, pesticides, as well as those naturally present in irrigation waters, are frequently applied to the field. The unsaturated zone can also be a receptacle for controlled waste storage and disposal. When water is applied to the soil surface, either by rain or irrigation, it may transport chemical contaminants through the unsaturated zone to the underlying groundwater aquifer. Because of the vulnerability of the unsaturated zone to contamination and its direct link to aquifers, a clear understanding of chemical transport, including proper quantification of relevant transport processes, is therefore important for both agricultural and environmental engineers. Mathematical models play a significant role in the analysis of the movement and fate of contaminants in porous media because of their contribution to the understanding of these processes.

The Richards equation (Richards, 1931) is often used to describe water movement in unsaturated soil, although serious mass balance and convergence problems can appear due to its non linear nature. The advection-dispersion equation (ADE) has been widely used to describe solute transport in porous media (Bear, 1979). Many algorithms exist in the literature for the numerical solution of the ADE. Finite elements and finite differences methods are classically used to solve the advectiondispersion equation. These methods often exhibit oscillatory behavior and/or excessive numerical dispersion near relatively sharp concentration fronts (e.g. Huyakorn and Pinder, 1983). These problems becomes serious for advective-dominated transport characterized by small dispersivities. One way to partially circumvent numerical oscillations is to use upstream weighting, or to subject these classical methods to a local grid Peclet $\left(\mathrm{P}_{\mathrm{e}}\right)$ and Courant $\left(\mathrm{C}_{\mathrm{r}}\right)$ numbers restrictions. Perrochet and Berod (1993) developed a criterion $\mathrm{P}_{\mathrm{e}} \cdot \mathrm{C}_{\mathrm{r}} \leq \gamma$ where $\gamma$ is the performance index $(\gamma \leq 2)$, which permits to minimize or eliminate numerical oscillations. The restriction on the Peclet number is 
achievable by using a fine spatial discretization which leads to high computational effort consideration. Upwind schemes (e.g. Peyret and Taylor, 1983) give first order accurate stable solution (with no oscillations), but with numerical diffusion smearing the front.

Eulerian-Lagrangian methods are an alternative which are less restrictive in space and time discretisation. The most popular are the method of characteristic (Garder et al., 1964) or the modified method of characteristics (Chiang et al., 1989). Other classes of Eulerain-Lagrangian methods have been developed in conjunction with weak formulation like Galerkin EulerianLagrangian (Neuman, 1981) or Eulerian-Lagrangian localized adjoint (Binning and Celia, 1996).

The objective of this study is to develop an alternative numerical model that is able to produce accurate simulations of transient flow and solute transport in 1-D unsaturated-saturated porous media. The flow model is based on the mixed form of Richard's equation and solved by standard finite element method coupled with a primary variable switching technique, which represents a fast and robust strategy for unsaturated problems (Diersch and Perrochet, 1999).

Operator and time splitting (e.g. Dawson and Wheeler, 1992) is used to solve the transport equation. It has been quite successful for solving the Navier-Stokes equations. It offers the possibility to adapt an accurate numerical technique for each kind of partial differential equation. Therefore, we adapt an high-order accurate and nonoscillatory finite element upwind scheme (Siegel et al., 1997 ; Toro, 1997) for the advective term of the transport equation. These schemes are generally constructed through a discontinuous piecewise polynomial representation of the solution (Van Leer, 1977) and are stabilized with slope limiters (Chavent and Jaffré, 1986). The dispersive term in the proposed model in discretized by finite differences.

The accuracy of the proposed model is evaluated by comparing its results with analytical solutions for saturated flow and with numerical solutions based on finite element model.

\section{The mathematical models}

The mathematical models are the standard models described by Richards (1931) and Bear (1979). 


\subsection{The flow equation}

The 1D vertical mathematical model used to describe fluid flow in partially saturated rigid porous media is obtained by combining the mass conservation equation with the generalized Darcy's law which leads to the mixed form of the Richards' equation (Richards, 1931):

$$
\frac{\partial \theta(\mathrm{h})}{\partial \mathrm{t}}-\frac{\partial}{\partial \mathrm{z}}\left[\mathrm{K}_{\mathrm{s}} \mathrm{k}(\mathrm{h})\left(\frac{\partial \mathrm{h}}{\partial \mathrm{z}}-1\right)\right]=0
$$

with $\mathrm{h}$, the pressure head $(\mathrm{L})(\mathrm{h}>0$ in saturated medium and $\mathrm{h} \leq 0$ in unsaturated medium); $\mathrm{k}(\mathrm{h})$ the relative hydraulic conductivity $(0<\mathrm{k}(\mathrm{h}) \leq 1, \mathrm{k}=1$ if $\mathrm{h} \geq 0)\left(\mathrm{L} \mathrm{T}^{-1}\right) ; \mathrm{K}_{\mathrm{S}}$ the saturated hydraulic conductivity $\left(\mathrm{L} \mathrm{T}^{-1}\right) ; \theta(\mathrm{h})$ the volumetric water content $\left(\mathrm{L}^{3} \mathrm{~L}^{-3}\right) ; \mathrm{z}$ the depth taken positive downwards (L) and the time (T).

Any initial condition in terms of pressure head or water content can be invoked. Dirichlet (pressure head) or Neumann (flux) boundary conditions at the top or bottom of the profile must be associated to the partial differential equations.

This mixed form of the Richards' equation is solved by the standard Galerkin finite element method (Pinder and Gray, 1977). A lumped time matrix (Celia et al., 1990; Milly, 1985; Van Genuchten, 1982) is used to speed up numerical convergence when simulating infiltration into dry porous medium, and to guarantee a smooth and non-oscillatory solution profile. The system of equations obtained is highly non-linear because of the nonlinear dependency of $\mathrm{K}$ and $\theta$ on $\mathrm{h}$. The most popular linearization techniques are the Picard, modified Picard also called fixed point method and the Newton methods. The Newton method described in Lehmann and Ackerer (1998) is used, improved by the primary variable switching technique suggested by Diersch and Perrochet (1999) to linearize the equation. 


\subsection{The transport equation}

In 1-D, the transport of a conservative constituent in a porous medium partially saturated with water without sink/source term can be represented by the following equation (Bear, 1979),

$$
\frac{\partial(\theta \mathrm{C})}{\partial \mathrm{t}}=\frac{\partial}{\partial \mathrm{z}}\left(\theta \mathrm{D} \frac{\partial \mathrm{C}}{\partial \mathrm{z}}\right)-\frac{\partial}{\partial \mathbf{z}}(\mathrm{qC})
$$

with $\mathrm{z}$ the depth taken positive downwards. In the very standard formulation, it is assumed that the dispersion coefficient is given by $\theta D=\lambda_{L}|q|+\theta D_{m} \tau$ where $|q|$ is the magnitude of the Darcy's velocity $\left(\mathrm{LT}^{-1}\right)$ and $\lambda_{\mathrm{L}} \quad$ is the longitudinal pore-scale dispersivities (L), generally considered to be an intrinsic property of the porous media under fully saturated condition. However, the dispersion might be a non linear function of the saturation (Maraqa et al., 1997; Forrer et al., 1999; Inoue et al., 2000). $\mathrm{D}_{\mathrm{m}}$ is the molecular diffusion coefficient in free water $\left(\mathrm{L}^{2} \mathrm{~T}^{-1}\right)$ and $\tau$ is the tortuosity factor, which is evaluated using the relationship of Millington and Quirk (1961) $\tau=\frac{\theta^{\frac{7}{3}}}{\theta_{\mathrm{s}}^{2}}, \theta_{\mathrm{s}}$ being the saturated water content $\left(\mathrm{L}^{3} \mathrm{~L}^{-3}\right)$.

Equation (2) is the divergence form of the advection-dispersion equation (ADE). It can be converted to the advective form which is considered to be more convenient for finite element discretization (Huyakorn et al., 1985). This is accomplished by expanding the advective and the mass accumulation terms and using the continuity equation for water flow (here without source/sink term):

$$
\frac{\partial \theta}{\partial t}+\frac{\partial \mathrm{q}}{\partial \mathrm{z}}=0
$$

Performing the necessary steps, we obtain

$$
\theta \frac{\partial \mathrm{C}}{\partial \mathrm{t}}+\mathrm{q} \frac{\partial \mathrm{C}}{\partial \mathrm{z}}=\frac{\partial}{\partial \mathrm{z}}\left(\theta \mathrm{D} \frac{\partial \mathrm{C}}{\partial \mathrm{z}}\right)
$$




\section{Numerical solution of the advection-dispersion equation}

To solve the transport equation, operator and time splitting are used. The ADE is split into two equations. The first equation describes advection and the second, dispersion. The advantage is that for each time step, a specialized scheme can be used to solve the advective term and a conventional algorithm can be used to solve the dispersive term (Hills et al., 1994). The operator splitting is applied to equation (4) to avoid assumptions on the time discretization of the water content which is required if the splitting is used for equation (2). Equation (4) is rewritten in the following form:

$$
\theta^{\mathrm{n}+1} \frac{\mathrm{C}^{\mathrm{n}+1}-\mathrm{C}^{\mathrm{adv}, \mathrm{n}+1}+\mathrm{C}^{\mathrm{adv}, \mathrm{n}+1}-\mathrm{C}^{\mathrm{n}}}{\Delta \mathrm{t}}+\mathrm{q}^{\mathrm{n}+1} \frac{\partial \mathrm{C}}{\partial \mathrm{z}}=\frac{\partial}{\partial \mathrm{z}}\left(\theta \mathrm{D} \frac{\partial \mathrm{C}}{\partial \mathrm{z}}\right)
$$

and is split in:

$$
\theta^{\mathrm{n}+1} \frac{\mathrm{C}^{\mathrm{adv}, \mathrm{n}+1}-\mathrm{C}^{\mathrm{n}}}{\Delta \mathrm{t}}+\mathrm{q}^{\mathrm{n}+1} \frac{\partial \mathrm{C}}{\partial \mathrm{z}}=0
$$

and

$$
\theta^{\mathrm{n}+1} \frac{\mathrm{C}^{\mathrm{n}+1}-\mathrm{C}^{\mathrm{adv}, \mathrm{n}+1}}{\Delta \mathrm{t}}=\left\{\frac{\partial}{\partial \mathrm{z}}\left(\theta \mathrm{D} \frac{\partial \mathrm{C}}{\partial \mathrm{z}}\right)\right\}^{\mathrm{n}+1}
$$

where $C^{\text {adv,n+1 }}$ is the concentration after advection for time $n+1$. Boundary and initial conditions are required to solve each partial differential equation. The water content is taken at time $n+1$ to be consistent with Darcy’s velocity q.

\subsection{Numerical solution of the advective term}

A discontinuous finite elements scheme (DFE) with slope limiters is used to discretize the advective term (Chavent and Jaffré, 1986). This scheme is applied to the divergence form of the advective transport. Therefore, equation (6a) is slightly modified to obtain:

$\theta \frac{\partial \mathrm{C}}{\partial \mathrm{t}}=-\frac{\partial}{\partial \mathrm{z}}(\mathrm{qC})+\mathrm{C} \frac{\partial \mathrm{q}}{\partial \mathrm{z}}$

The one-dimensional space interval $[0, \mathrm{~L}]$ is discretized with a set of elements $\mathrm{E}=\left\lfloor\mathrm{z}_{\mathrm{i}}, \mathrm{z}_{\mathrm{j}}\right\rfloor$ and nodes $\mathrm{z}_{1}=0<\ldots<\mathrm{z}_{\mathrm{j}}<\ldots \mathrm{z}_{\mathrm{I}+1}=\mathrm{L}$. We denote by $\Delta \mathrm{z}_{\mathrm{E}}$ the size of element $\mathrm{E}$. The concentration $\mathrm{C}$ is 
approximated in a space of discontinuous linear functions. The concentration over element $\mathrm{E}\left(\mathrm{C}_{\mathrm{E}}\right)$ is a linear combination of the two bases functions $\mathrm{w}_{\mathrm{E} 1}$ and $\mathrm{w}_{\mathrm{E} 2}$ associated to element $\mathrm{E}$. The linear variation in $\mathrm{C}$ over $\mathrm{E}$ is defined as :

$\mathrm{C}_{\mathrm{E}}(\mathrm{z})=\mathrm{w}_{\mathrm{i}}(\mathrm{z}) \mathrm{C}_{\mathrm{i}}+\mathrm{w}_{\mathrm{i}+1}(\mathrm{z}) \mathrm{C}_{\mathrm{i}+1} \quad$ for $\mathrm{z}_{\mathrm{i}} \leq \mathrm{z} \leq \mathrm{z}_{\mathrm{i}+1}$

where:

$\mathrm{w}_{\mathrm{i}}(\mathrm{z})=\frac{\mathrm{z}_{\mathrm{i}+1}-\mathrm{z}}{\mathrm{z}_{\mathrm{i}+1}-\mathrm{z}_{\mathrm{i}}}, \mathrm{w}_{\mathrm{i}+1}(\mathrm{z})=\frac{\mathrm{z}-\mathrm{z}_{\mathrm{i}}}{\mathrm{z}_{\mathrm{i}+1}-\mathrm{z}_{\mathrm{i}}}, \mathrm{C}_{\mathrm{i}}$ and $\mathrm{C}_{\mathrm{i}+1}$ the concentration at node $\mathrm{i}$ and $\mathrm{i}+1$ of element E, respectively. The function $\mathrm{C}$ defined over the whole domain is discontinuous at the nodes of discretization, so we denote by $C_{i}^{\text {in }}$ et $C_{i}^{\text {out }}$ the inside and outside value of $C$ at node $i$, with respect to element E. A variational form of equation (7) is obtained over element $\mathrm{E}$ as follows:

$\int_{\mathrm{E}} \theta \frac{\partial \mathrm{C}}{\partial \mathrm{t}} \mathrm{wdz}=-\int_{\mathrm{E}} \frac{\partial(\mathrm{qC})}{\partial \mathrm{z}} \mathrm{wdz}+\int_{\mathrm{E}} \mathrm{C} \frac{\partial \mathrm{q}}{\partial \mathrm{z}} \mathrm{wdz}$

where $\mathrm{w}$ is one of the basis function defined over $\mathrm{E}$.

Using the Green formula, the equation becomes:

$\int_{E} \theta_{E} \frac{\partial C_{E}}{\partial t} w d z=\int_{E} q_{E} C_{E} \cdot \frac{\partial w}{\partial z} d z-\bar{q}_{E, i+1} C_{i+1}^{\text {in or out }} w\left(z_{i+1}\right)+\bar{q}_{E, i} C_{i}^{\text {in or out }} w\left(z_{i}\right)+\int_{E} C_{E} \frac{\partial q}{\partial z} w d z$

where $\overline{\mathrm{q}}_{\mathrm{E}, \mathrm{i}}$ and $\overline{\mathrm{q}}_{\mathrm{E}, \mathrm{i}+1}$ are the fluxes at node $\mathrm{i}$ and $\mathrm{i}+1$ of element $\mathrm{E}$, respectively; $\theta_{\mathrm{E}}$ being the water content over the element $\mathrm{E}$. The out-flux is defined positive and the in-flux negative.

To preserve mass balance, the advective fluxes have to be uniquely defined at the interface of two elements. These fluxes are obtained by solving a standard Riemann problem (Gowda and Jaffré, 1994), the numerical advective flux is calculated with the upstream value of $C_{i}$ (Figure 1):

$$
\begin{aligned}
\text { if } \overline{\mathrm{q}}_{\mathrm{E}, \mathrm{i}} \leq 0 \quad \mathrm{C}_{\mathrm{i}}=\mathrm{C}_{\mathrm{i}}^{\text {out }} \\
\text { if } \overline{\mathrm{q}}_{\mathrm{E}, \mathrm{i}} \geq 0_{\mathrm{i}} \quad \mathrm{C}_{\mathrm{i}}=\mathrm{C}_{\mathrm{i}}^{\text {in }}
\end{aligned}
$$

An explicit second order scheme is used for time discretization to improve the accuracy of the calculation. Therefore, the computation is done in two steps: 
1. an intermediate time step at time $\mathrm{t}^{\mathrm{n}+1 / 2}$ is defined, where the advective fluxes are calculated using the concentration values defined inside element $\mathrm{E}$ :

$$
\begin{aligned}
& \int_{E} \theta_{E}^{n+1} \frac{\left(C_{E}^{n+1 / 2}-C_{E}^{n}\right)}{1 / 2 \Delta t^{n}} w d z=\int_{E} q_{E}^{n+1} C_{E}^{n} \frac{\partial w}{\partial z} d z-\bar{q}_{E, i+1}^{n+1} C_{i+1}^{i n, n} w\left(z_{i+1}\right)+\bar{q}_{E, i}^{n+1} C_{i}^{i n, n} w\left(z_{i}\right) \\
& +\int_{E} C_{E}^{n} \frac{\partial q}{\partial z} w d z
\end{aligned}
$$

with $\Delta \mathrm{t}^{\mathrm{n}}=\mathrm{t}^{\mathrm{n}+1}-\mathrm{t}^{\mathrm{n}}$.

2. The Riemann problem is solved in the second step:

$$
\begin{aligned}
& \int_{E} \theta_{E}^{n+1} \frac{\left(C_{E}^{n+1^{*}}-C_{E}^{n}\right)}{\Delta t^{n}} w d z=\int_{E} q_{E}^{n+1} C_{E}^{n+1 / 2} \frac{\partial w}{\partial z} d z-\bar{q}_{E, i+1}^{n+1} C_{i+1}^{\text {in or out }, n+1 / 2} w\left(z_{i+1}\right) \\
& +\bar{q}_{E, i}^{n+1} C_{i}^{\text {in or out }, n+1 / 2} w\left(z_{i}\right)+\int_{E} C_{E}^{n+1 / 2} \frac{\partial q}{\partial z} w d z
\end{aligned}
$$

By using successively $\mathrm{w}_{\mathrm{E} 1}$ and $\mathrm{w}_{\mathrm{E} 2}$ as test functions, a system of two equations and two unknowns per element, $\mathrm{C}_{\mathrm{i}}^{\mathrm{in}, \mathrm{n}+1}$ and $\mathrm{C}_{\mathrm{i}+1}^{\mathrm{in}, \mathrm{n}+1}$, is obtained. DFE method requires the computation of the velocity through the element and at each nodes (see equations 12 or 13). The velocity inside the element is computed using Darcy's law, the heads calculated at each node and the hydraulic conductivity. Finite element methods do not provide continuous velocities at nodes. We compute an average value of the two nodal velocities. This computation can lead to small water balance error at the element level (less than $2 \%$ for the studied cases). However, these errors have no effect on the solute mass balance due to the discretization of the accumulation term.

After these two steps, the solution $\mathrm{C}_{\mathrm{i}}^{\mathrm{n}+1^{*}}$ is improved by slope limiting. Because advection does not increase the variation of concentration inside the modeled domain, the advection equation is Total Variation Diminishing (TVD). Therefore, slope limiters can be used to avoid oscillations. Detailed presentation and mathematical justification of TVD methods and slope limiters can be found in the book of Toro (1997). 
The slope limiting process satisfies the following conditions :

1. mass preservation:

$$
\overline{\mathrm{C}}_{\mathrm{E}}^{\mathrm{n}+1}=\int_{\mathrm{E}} \frac{\mathrm{C}_{\mathrm{E}}^{\mathrm{n}+1}}{\Delta \mathrm{z}_{\mathrm{E}}} \mathrm{dz}=\left(\mathrm{C}_{\mathrm{i}}^{\mathrm{in}, \mathrm{n}+1}+\mathrm{C}_{\mathrm{i}+1}^{\mathrm{in}, \mathrm{n}+1}\right) / 2=\overline{\mathrm{C}}_{\mathrm{E}}^{\mathrm{n}+1^{*}}=\left(\mathrm{C}_{\mathrm{i}}^{\mathrm{in}, \mathrm{n}+1^{*}}+\mathrm{C}_{\mathrm{i}+1}^{\mathrm{in}, \mathrm{n}+1^{*}}\right) / 2
$$

2: in order to avoid oscillations

$$
\begin{aligned}
& \min \left(\overline{\mathrm{C}}_{\mathrm{E}-1}^{\mathrm{n}+1^{*}}, \overline{\mathrm{C}}_{\mathrm{E}}^{\mathrm{n}+1^{*}}\right) \leq \mathrm{C}_{\mathrm{i}}^{\mathrm{in}, \mathrm{n}+1} \leq \max \left(\overline{\mathrm{C}}_{\mathrm{E}-1}^{\mathrm{n}+1^{*}}, \overline{\mathrm{C}}_{\mathrm{E}}^{\mathrm{n}+1^{*}}\right) \\
& \min \left(\overline{\mathrm{C}}_{\mathrm{E}+1}^{\mathrm{n}+1^{*}}, \overline{\mathrm{C}}_{\mathrm{E}}^{\mathrm{n}+1^{*}}\right) \leq \mathrm{C}_{\mathrm{i}+1}^{\mathrm{in}, \mathrm{n}+1} \leq \max \left(\overline{\mathrm{C}}_{\mathrm{E}+1}^{\mathrm{n}+1^{*}}, \overline{\mathrm{C}}_{\mathrm{E}}^{\mathrm{n}+1^{*}}\right)
\end{aligned}
$$

Physically, the previous relations specify that $C_{i}^{i n, n+1}$ and $C_{i+1}^{i n, n+1}$ are not greater or smaller than the mean concentration in the elements $\mathrm{E}-1, \mathrm{E}, \mathrm{E}+1$ (Figure 2). If $\overline{\mathrm{C}}_{\mathrm{E}}^{\mathrm{n}+1^{*}}$ is a local maximum or minimum, then $\mathrm{C}_{\mathrm{i}}^{\mathrm{in}, \mathrm{n}+1}=\overline{\mathrm{C}}_{\mathrm{E}}^{\mathrm{n}+1^{*}}$.

This procedure has been extended in 2 or 3 dimensions (Siegel et al., 1997). In that case, if $\overline{\mathrm{C}}_{\mathrm{E}}^{\mathrm{n}+1^{*}}$ is not a local maximum or minimum, the concentration at node $\mathrm{i}$ of element $\mathrm{E}$ is not uniquely defined. An optimization procedure (saddle point method) is used to minimize the following objective function $\mathrm{J}$ :

$J(p)=\sum_{i=1}^{n}\left\|C_{i}^{i n, n+1}-C_{i}^{i n, n+1^{*}}\right\|^{2}$

where $\mathrm{p}$ represents the concentrations of the inner node of element $\mathrm{E}$ and $\mathrm{n}$ the number of nodes of element $\mathrm{E}$, i.e. $\mathrm{C}_{\mathrm{i}}^{\mathrm{in}, \mathrm{n}+1}$ should be as close as possible to $\mathrm{C}_{\mathrm{i}}^{\mathrm{in}, \mathrm{n}+1^{*}}$.

\subsection{Numerical solution of the dispersive term:}

The dispersive term is discretized with an implicit standard finite differences approximation. Associated with its boundary conditions, equation (6b) becomes :

$$
\Delta \mathrm{z}_{\mathrm{E}} \theta_{\mathrm{E}}^{\mathrm{n}+1}\left(\frac{\mathrm{C}_{\mathrm{E}}^{\mathrm{n}+1}-\mathrm{C}_{\mathrm{E}}^{\mathrm{adv}, \mathrm{n}+1}}{\Delta \mathrm{t}^{\mathrm{n}}}\right)=\left(\theta^{\mathrm{n}+1} \mathrm{D}^{\mathrm{n}+1}\right)_{\mathrm{E}-1, \mathrm{E}}\left(\frac{\mathrm{C}_{\mathrm{E}-1}^{\mathrm{n}+1}-\mathrm{C}_{\mathrm{E}}^{\mathrm{n}+1}}{\Delta \mathrm{z}_{\mathrm{E}}}\right)+\left(\theta^{\mathrm{n}+1} \mathrm{D}^{\mathrm{n}+1}\right)_{\mathrm{E}, \mathrm{E}+1}\left(\frac{\mathrm{C}_{\mathrm{E}+1}^{\mathrm{n}+1}-\mathrm{C}_{\mathrm{E}}^{\mathrm{n}+1}}{\Delta \mathrm{z}_{\mathrm{E}}}\right)
$$


where $\Delta \mathrm{z}_{\mathrm{E}}$ is the element length which is assumed to be constant over the depth for simplicity and $\Delta \mathrm{t}^{\mathrm{n}}$ is the time step.

$\left(\theta^{\mathrm{n}+1} \mathrm{D}^{\mathrm{n}+1}\right)_{\mathrm{E}-1, \mathrm{E}}$ is the equivalent dispersion coefficient estimated by the harmonic mean of the water content and dispersion coefficient defined at the element level E and E-1.

Equation (16) is modified in a standard way to describe Dirichlet or Neumann boundary conditions.

\section{Test problems}

Test problems were designed to demonstrate the performance of our model in a variety of rigorous problems. The numerical results are compared to analytical solutions when they exist, or to numerical results obtained by an improved finite element method (Van Genuchten, 1978). This method is coded in Hydrus-1D (Simunek et al., 1998), which is a widely used software. Different kind of discretizations are available in Hydrus-1D : an improved finite elment method (FEM), an upstream weighted formulation and a stabilization option with artificial dispersion (Perrochet and Berod, 1993). The two last formulations avoid oscillations but create artificial dispersion, which is too important for high grid Peclet numbers. Therefore, all computations are run with FEM.

The hydrodynamics properties are represented by Mualem (1976) and Van Genuchten equations (Van Genuchten, 1980):

$$
\begin{cases}S=\frac{\theta-\theta_{r}}{\theta_{s}-\theta_{r}}=\frac{1}{\left[1+(\alpha|h|)^{n}\right]^{1-1 / n}} & \text { if } h \leq 0 \\ S=1 & \text { if } h \geq 0\end{cases}
$$

and

$$
\mathrm{K}=\mathrm{K}_{\mathrm{s}} \sqrt{\mathrm{S}}\left[1-\left(1-\mathrm{S}^{(\mathrm{n} / \mathrm{n}-1)}\right)^{(1-(1 / \mathrm{n}))}\right]^{2} \text { with } \mathrm{n}>1
$$

where $\theta_{\mathrm{s}}\left(\mathrm{L}^{3} \mathrm{~L}^{-3}\right)$ and $\theta_{\mathrm{r}}\left(\mathrm{L}^{3} \mathrm{~L}^{-3}\right)$ are the saturated and residual water content, respectively, $\mathrm{S}$ is relative saturation, $\mathrm{K}_{\mathrm{s}}\left(\mathrm{LT}^{-1}\right)$ is the saturated hydraulic conductivity, and $\alpha\left(\mathrm{L}^{-1}\right)$ and $\mathrm{n}(-)$ are empirical constants determining the shape of the functions. 
Two dimensionless numbers are used to characterize the space and time discretizations:

- the grid Peclet number, $\mathrm{P}_{\mathrm{e}}=\frac{\mathrm{q} \Delta \mathrm{z}}{\theta \mathrm{D}}$

- the Courant number, $\mathrm{C}_{\mathrm{r}}$ or Courant Friedrich Levy number $(\mathrm{CFL}), \mathrm{C}_{\mathrm{r}}=\frac{\mathrm{q} \Delta \mathrm{t}}{\theta \Delta \mathrm{z}}$

Explicit schemes require $\mathrm{C}_{\mathrm{r}} \leq 1$ to avoid oscillations and is also recommended to reduce numerical dispersion and/or oscillations in concentration distribution for implicit schemes (e.g. Kinzelbach, 1986). To provide accurate results, the grid Peclet number should be smaller than 2 for standard numerical schemes like finite differences of finite element (e.g. Kinzelbach, 1986).

\subsection{Test problem $n^{\circ} 1$}

The first test case deals with a 1D saturated porous media. The flow field is steady state which simplifies the problem, the accumulation term being equal to zero. Darcy's velocity is constant (Table 1). The numerical results of the proposed model, Wamos-T, is compared to the analytical solution of Ogata and Banks (1961) and to a finite element model (FEM).

Three computations have been run with different grid Peclet number (Table 1 , Test $\mathrm{n}^{\circ} 1$ ). The first computation runs over 15 minutes, the two others over 20 minutes. The Courant number is less than one for all computations.

The solution based on discontinuous finite elements matches the analytical solution quite well for the two first computations. For higher grid Peclet number, the solution remains stable due to the slope limiting procedure (Figure 3). However, this procedure generates some numerical diffusion (Figure 4). The numerical solution produced by the FEM provides accurate results for low grid Peclet number (Table 1 , Test $\mathrm{n}^{\circ} 1$ Case 1 ) and gives good results compare to the analytical solution but oscillates for the two other computations (Table 1, Test $\mathrm{n}^{\circ} 1$ Cases 2 and 3 ) as expected for these ranges of Peclet number (Figure 3 and 4). 


\subsection{Test problem $n^{\circ} 2$}

This test problem deals with infiltration of water and non reactive solute into homogeneous soil under fully unsaturated conditions. The objective of this test is to verify the discretization of the accumulation term for the DFE method under transient flow field conditions.

The hydrodynamics and transport parameters and the initial and boundary conditions are summarized in Table 1 , Test $\mathrm{N}^{\circ} 2$. The simulations are performed over 12 and 24 hours for three grid Peclet numbers: $\mathrm{Pe}=0.20, \mathrm{Pe}=10$ and $\mathrm{Pe}=100$ (Table 1, Test $\mathrm{N}^{\circ} 2$ Case 1,2 and 3).

For the grid Peclet numbers of 0.20 and 10, both models provide similar results. Standard finite element models usually oscillates for grid Peclet numbers greater than 5. For the FEM, the improvements suggested by Van Genuchten (1978) significantly increases the robustness and accuracy of the simulation. For the highest grid Peclet number $(\mathrm{Pe}=100)$, the results obtained by Wamos-T remains unchanged whereas oscillations appear for FEM (Figure 5).

\subsection{Test problem $n^{\circ} 3$}

In this test problem, we perform the simulation of infiltration of water and non reactive solute into heterogeneous soil. The objective is to verify the accuracy of the proposed numerical scheme to abrupt changes in water content. The domain is a layered column consisting of alternating layers of sand and clay (Hills et al., 1989). Each layer has a thickness of $20 \mathrm{~cm}$, the model is a five layers system, with a sand layer on top. This test problem has been suggested by Segol (1993).

The material properties for the two soils are described by Van Genuchten's relations. The hydraulic and transport parameters and the other simulation parameters are summarized in Table $1, \mathrm{Test}^{\circ} 3$. The simulations are performed over 5 and 10 days. The water content profiles (Figure 6) obtained by both codes are very similar. Both numerical models provide accurate results (Figure 7). We observe little oscillations with the FEM, while the Wamos-T profile shows no oscillations. The numerical schemes used in Wamos-T provide also accurate results for heterogeneous media. 


\subsection{Test problem $n^{\circ} 4$}

The model is applied to a problem involving vertical infiltration and evaporation of water with an input of a non reactive solute flux during infiltration and a zero solute flux boundary during evaporation (Table 1 Test $\mathrm{N}^{\circ} 4$ and Figure 8). Infiltration/evaporation will provide abrupt changes in the velocity in orientation and magnitude. The total time of simulation is 12 days.

The first computation performed with a grid Peclet number of 4 shows very large discrepancies between the both numerical models (Figure 9). The results obtained by the DFE method remain practically unchanged with grid refinement whereas the results obtained by FEM converge to the results obtained with the DFE (Figures 10).

\section{Conclusion}

A new one-dimensional numerical model for simulating non reactive solute transport in saturatedunsaturated porous media is proposed. Operator splitting is used to adapt the numerical scheme to the partial differential equation (PDE): discontinuous finite element combined with a slope limiting procedure for advection (hyperbolic type of PDE) and finite differences for dispersion (parabolic type of PDE). The accuracy and robustness of the model has been demonstrated by comparing the results with analytical or numerical solutions for the following cases:

- $\quad$ saturated steady state flow with dispersive or advective dominated transport;

- transient unsaturated flow in a homogeneous porous medium;

- transient unsaturated flow in a heterogeneous domain with abrupt changes in water content;

- transient unsaturated flow in a homogeneous porous medium with time variable boundary conditions. These conditions creates velocity fluctuations in magnitude and direction.

The accuracy of the solutions obtained with this model for each test cases shows that the assumption made in the numerical formulation are verified. The Wamos-T model is a good alternative for the simulation of mass transport in unsaturated porous media, especially for grid Peclet numbers higher than 10 and for strong variable flow field due to heterogeneity or/or time 
varying flow boundary conditions. The explicit scheme in the discontinuous finite element need to respect the Courant number. For all the presented computations, the time step required for convergence for the flow calculation fulfilled the Courant criterion.

\section{Acknowledgments}

The authors would like to thank the Agence Universitaire de la Francophonie (AUF) by supporting El Hadji Bamba DIAW during his post-doctoral research at Institut de Mécanique des Fluides et des Solides de Strasbourg UMR 7507 ULP-CNRS and the French National Research Center (CNRS). We also would like to acknowledge the valuable comments and suggestions we received from $\mathrm{J}$. Šimůnek and an anonymous reviewer. 


\section{References}

Binning, P., Celia, M. A., 1996. A finite volume Eulerian-Lagrangian localized adjoint method for solution of the contaminant transport equations in two-dimensional multiphase flow systems. Water Resources. Res. 32 (1), 103-114.

Bear, J., 1979. Hydraulics of groundwater, McGraw-Hill, New York.

Celia, M. A., Bouloutas, E. T., Zarba, R. L., 1990. A general mass-conservative numerical solution for the unsaturated flow equation. Water Res. Res. 26 (7), 1483-1496.

Chavent G., Jaffré, J., 1986. Mathematical models and finite element for reservoir simulation. North Holland, Amsterdam.

Chiang, C.Y., Wheeler, M.F., Bedient, P.B., 1989. A modified method of the characteristics technique and mixed finite element method for simulation of ground water solute transport. Water Resources. Res. 25 (7), 1541-1549.

Dawson, C. N., Wheeler, M. F., 1992. Time splitting methods for advection-diffusion-reaction equations arising in contaminant transport. In Industrial and Applied Mathematics, Ed. O’Malley, SIAM, 71-82.

Dierch, H.-J. G., Perrochet, P., 1999. On the primary variable switching technique for simulating unsaturated-saturated flows. Advances in Water Resources, 23, 271-301.

Forrer I., Kasteel R., Flury M., Flühler H., 1999. Longitudinal and lateral dispersion in unsaturated field soil. Water Resources Research, 35(10), 3049-3060.

Garder, A.O., Peaceman, D.W., Pozzi, L.A., 1964. Numerical calculations of multidimensional miscible displacement by the method of characteristics. Soc. Pet. Eng., 4, 26-36.

Gowda, V., Jaffré, J., 1994. A discontinuous finite element method for scalar nonlinear conservation laws. Rapport de recherche INRIA.

Hills, R. G., Hudson, D.B., Porro, I., Wierrenga, P. J., 1989. Modeling One-dimensional infiltration into very dry soils, 2. Estimation of soil water parameters and Model Predictions. Water Resources Res. 25 (6), 1271-1282.

Hills, R.G., Fisher, K.A., Kirkland, M.R., Wierenga, P.J., 1994. Application of flux-corrected transport to the Las Cruses Trench site. Water Res. Res. 30 (8), 2377-2385.

Huyakorn, P. S., Pinder, G. F., 1983. Computational methods in subsurface flow, Academic Press, London, United Kingdom. 
Huyakorn, P. S., Mercer, J. W., Ward D. S., 1985. Finite Element Matrix and Mass Balance Computational Schemes for Transport in Variably Saturated Porous Media. Water Resources. Res. 21 (3):346-358.

Inoue, M., Šimůnek J., Shiozawa S., Hopmans J.W., 2000. Simultaneous estimation of soil hydraulic and solute transport parameters from transient infiltration experiments. Advances in Water Resources 23(7):677-688.

Kinzelbach, W., 1986. Groundwater modelling. An introduction with sample programs in BASIC. Developments in Water Sciences, Elsevier Pub., 333p.

Lehmann, F., Ackerer, Ph., 1998. Comparison of iterative methods for improved solutions of the fluid flow equation in partially saturated porous media. Transport in porous media, 31 (3) : 275-292.

Maraqa M. A., Wallace R. B., Voice T. C., 1997. Effects of degree of water saturation on dispersivity and immobile water in sandy soil columms. Journal of Contaminant Hydrology 25(3-4):199-218.

Milly, P. C. D., 1985. A mass-conservative procedure for time-stepping in models of unsaturated flow. Advances in Water Resources. 8, 32-36.

Millington, R. J., Quirk, J. M., 1961. Permeability of porous solids. Trans. Faraday Soc. 57, 12001207.

Mualem, Y., 1976. A vew model for predicting hydraulic conductivity of unsaturated porous media, Water Resources Res. 12 (3), 513-522.

Neuman, S.P., 1981. A eulerian-lagrangian numerical scheme for the dispersion convection equation using conjugate space time grids. J. Comp. Physics, 41, 270-294.

Ogata, A., Banks, R. B., 1961. A solution of differential equation of longitidunal dispersion in porous media. US Government printing office, Washington, DC.

Perrochet, P., Berod, D., 1993. Stability of the standard Crank-Nicholson-galerkin Scheme Applied to the diffusion-convection Equation: Some New Insights. Water Resources. Res. 29 (9), 3291-3297.

Peyret, R., Taylor, T.D., 1983. Computational Methods for fluid flow, Spring-Verlag, New York.

Pinder, G. F., Gray, W. G., 1977. Finite Element Simulation in Surface and Subsurface Hydrology. Academic Press.

Richards, L. A., 1931. Capillary conduction of liquids through porous medium. Physics. 1, 318-333. 
Ségol, G., 1993. Classic groundwater simulations: proving and improving numerical models. PTR Prentice Hall, Englewood Cliffs, New Jersey 07632, 531p.

Siegel, P.; Mosé R., Ackerer, Ph, Jaffré J., 1997. Solution of the advection-diffusion equation using a combination of discontinuous and mixed finite elements. International Journal for Numerical Methods in Fluids, vol. 24, 595-613.

Šimůnek, J., Sejna, M., Van Genuchten, M. Th., 1998. The HYDRUS-1D software Package for simulating the One-Dimensional Movement of Water, Heat, and Multiple Solutes in VariablySaturated Media. U. S. Salinity Laboratory, Agricultural Research Service, U. S Department of Agriculture, Riverside, California.

Toro, E. F., 1997. Riemann solvers and numerical methods for fluid dynamics : a practical introduction. Springer Verlag.

Van Genuchten, M. Th., 1978. Mass transport in saturated-unsaturated porous media : one dimensional solutions. Research report 78-WR-11, Water Resources Program, Princeton University.

Van Genuchten, M. Th., 1980. A closed-form equation for predicting the hydraulic conductivity of unsaturated soils. Soil Sci. Soc. Am. J., 44, 892-898.

Van Genuchten, M. Th., 1982. A comparison of numerical solution of the one dimensional unsaturated-saturated flow and mass transport equations. Advances in Water Resources. 5, 47-55.

Van Leer, B., 1977. Towards the ultimate conservative scheme : IV. A new approach to numerical convection, J. Comp. Phys., 23, 276-299. 


\section{Table caption}

Table 1 : Parameters for the Test Problems 
Table 1 : Parameters for the Test Problems

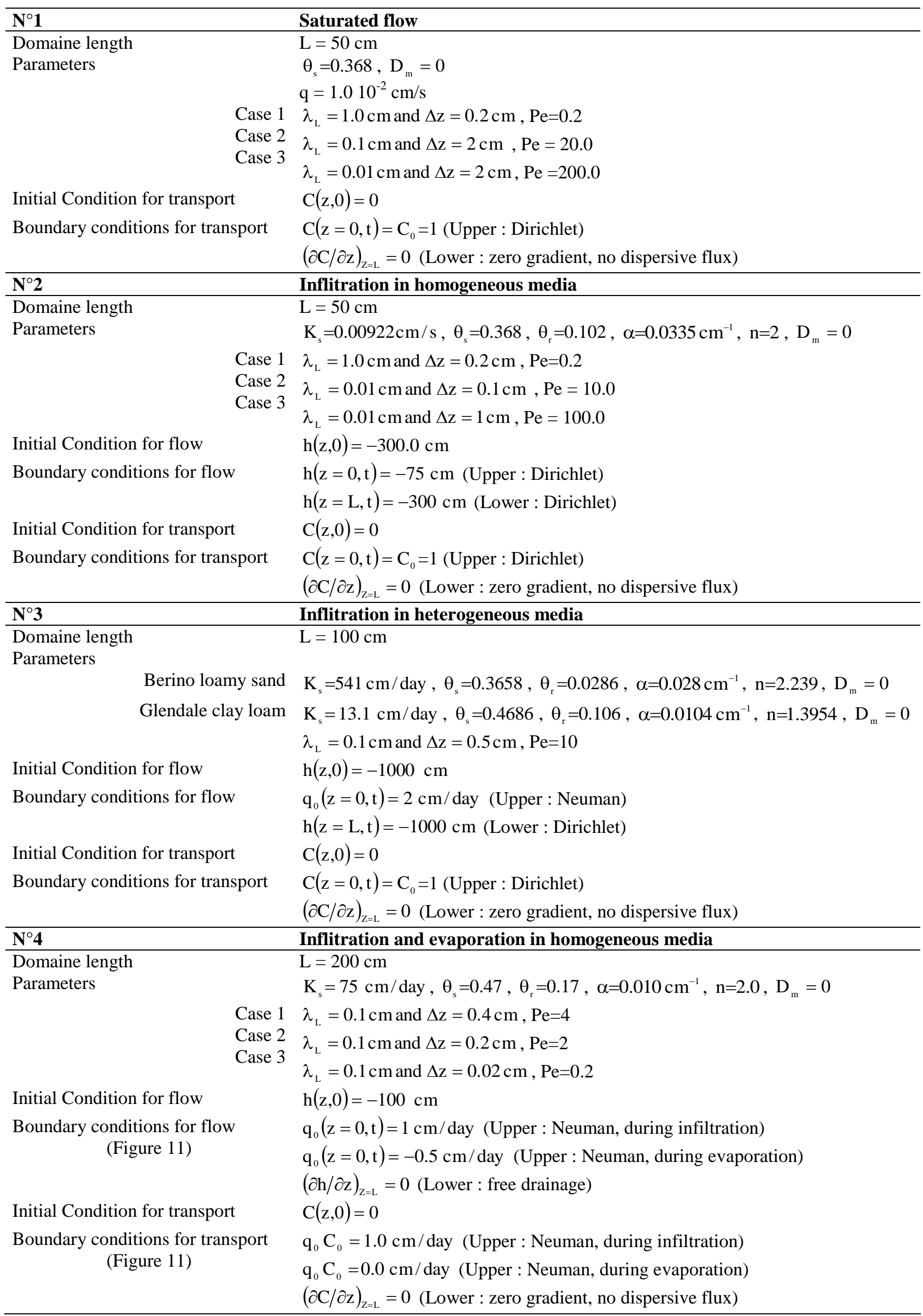




\section{Figure captions}

Figure 1 : Illustration of the discontinuous limit values of $C$ at nodes $z_{i}$ and $z_{i+1}$.

Figure 2: Slope limiting effects : linear discontinuous variation in concentration before (__ $)$ and after (—) slope limiting

Figure 3: Test case 1: normalized concentration profile after $20 \mathrm{mn}$ with $\mathrm{Pe}=20$.

Figure 4 : Test case 1: normalized concentration profile after $20 \mathrm{mn}$ with $\mathrm{Pe}=200$.

Figure 5 : Test case 2: normalized concentration profile after 12 and 24 hours with $\mathrm{Pe}=100$

Figure 6 : Test case 3: water-content profiles at $t=5$ days.

Figure 7 : Test case 3: normalized concentration profile after 5 and 10 days with $P e=10$.

Figure 8 : Test case 4: boundary conditions at the top of the profile.

Figure 9 : Test case 4: normalized concentration profile after 1,6 and 12 days with $\Delta \mathrm{z}=0.4 \mathrm{~cm}$.

Figure 10 : Test case 4: normalized concentration profile after 1,6 and 12 days with $\Delta \mathrm{z}=0.2 \mathrm{~cm}$ and $\Delta \mathrm{z}=0.02 \mathrm{~cm}$ for FEM and $\Delta \mathrm{z}=0.4 \mathrm{~cm}$ for Wamos-T. 


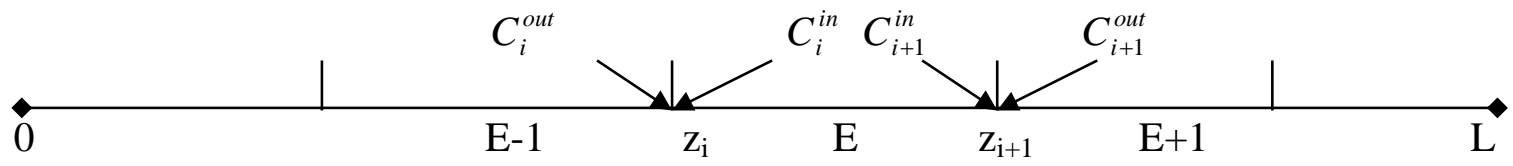

Figure 1 : Illustration of the discontinuous limit values of $C$ at nodes $z_{i}$ and $z_{i+1}$.

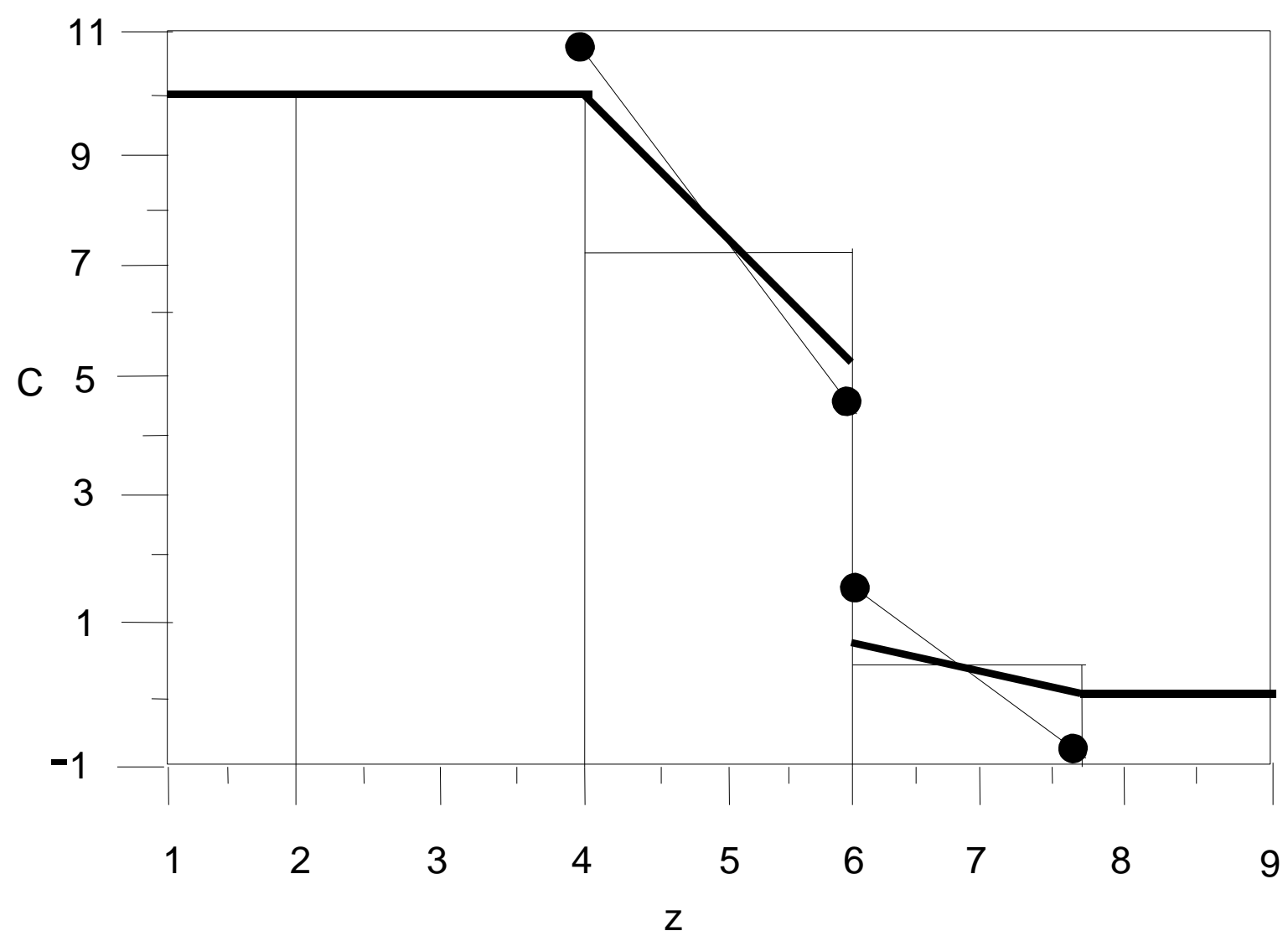

Figure 2: Slope limiting effects : linear discontinuous variation in concentration before $\left(\_\right)$and after (ـ) slope limiting 


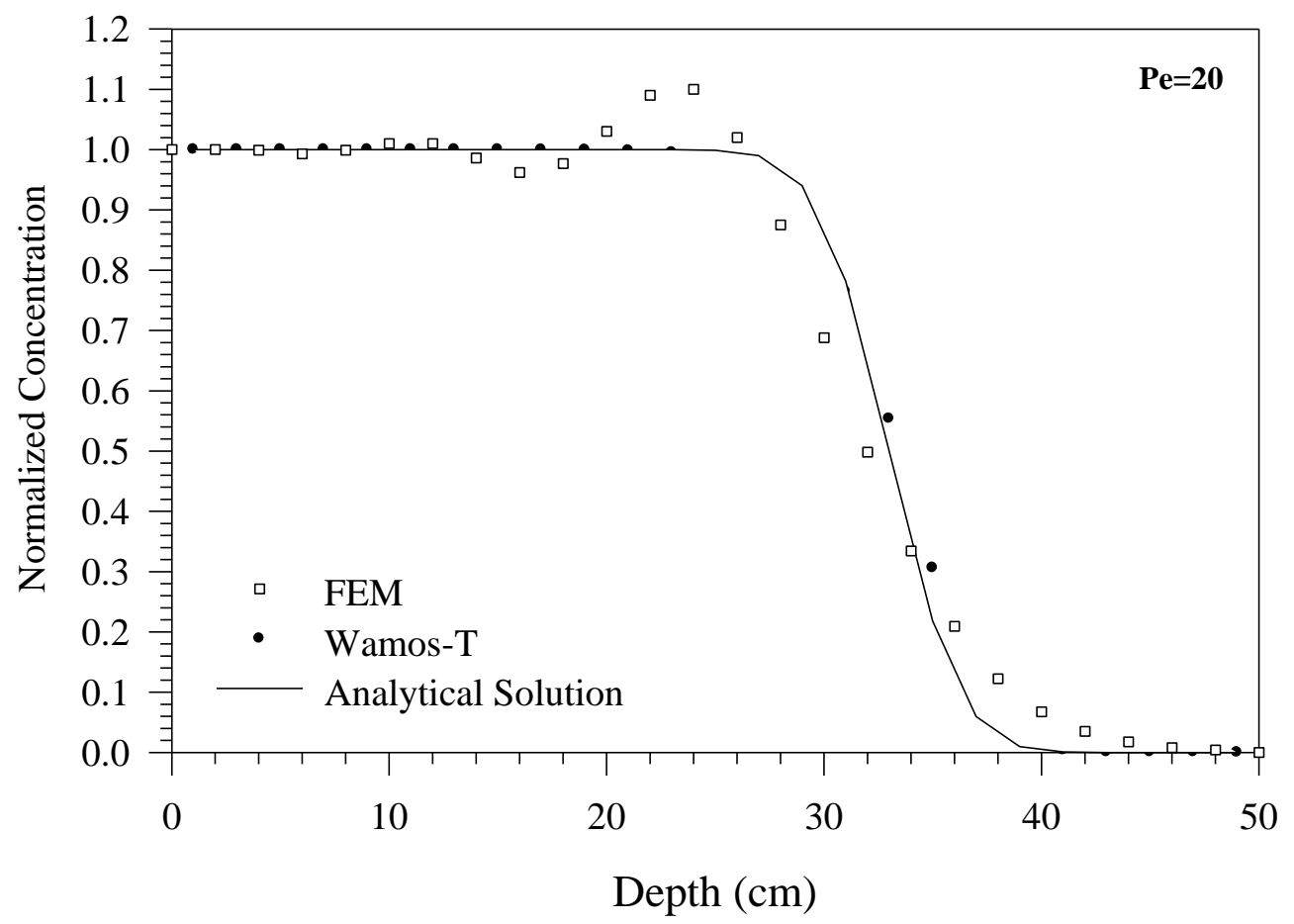

Figure 3: Test case1 : normalized concentration profile after $20 \mathrm{mn}$ with $\mathrm{Pe}=20$.

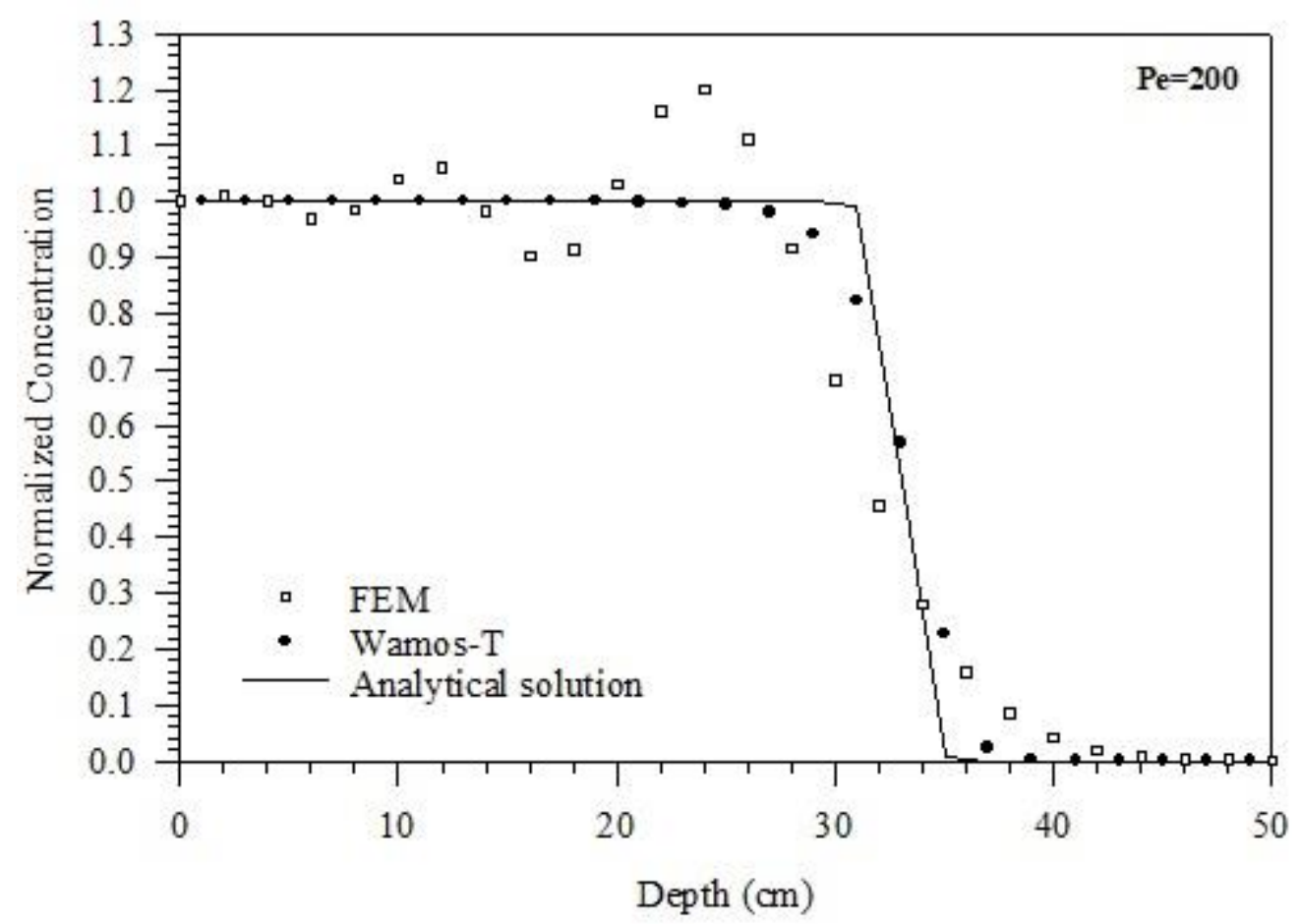

Figure 4 : Test case 1: normalized concentration profile after $20 \mathrm{mn} \mathrm{Pe}=200$. 


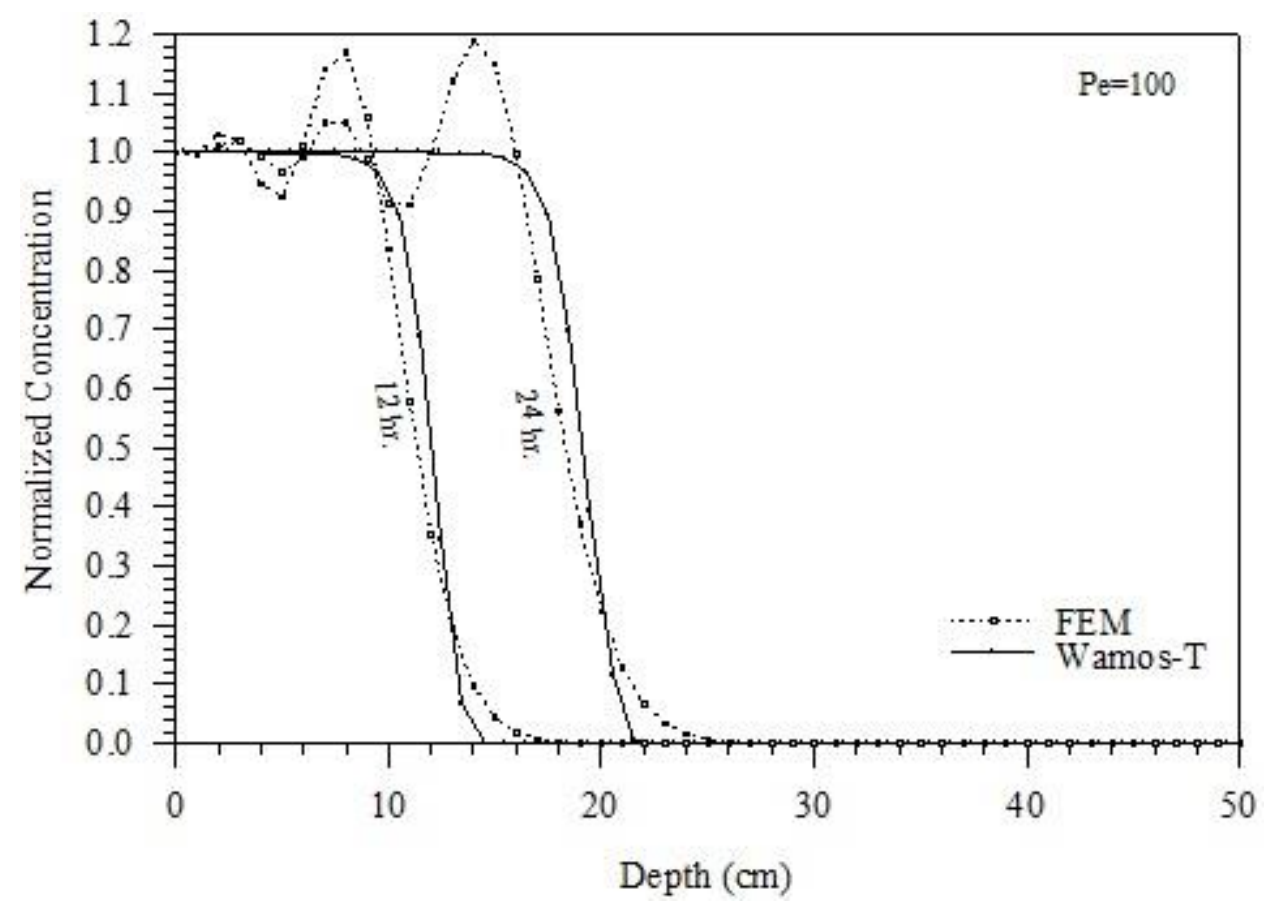

Figure 5 : Test case 2: normalized concentration profile after 12 and 24 hours with $\mathrm{Pe}=100$

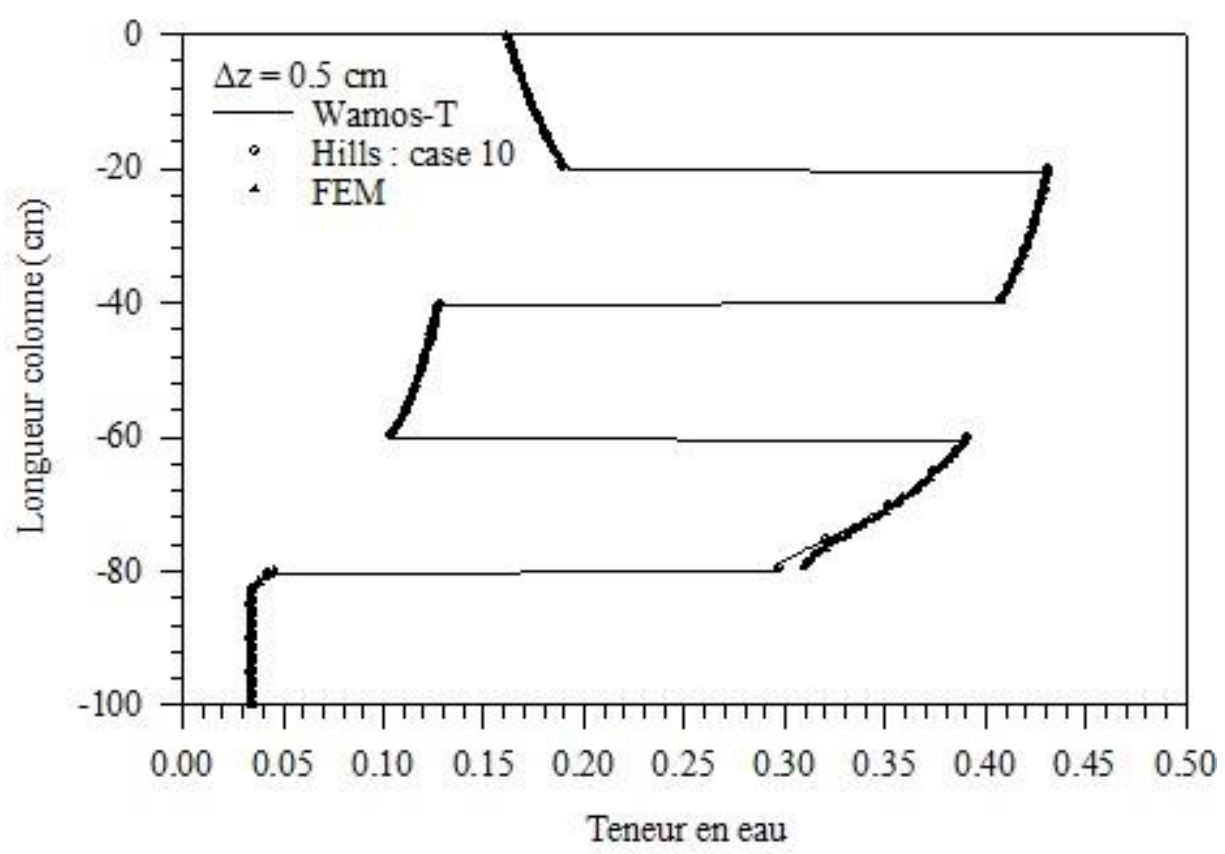

Figure 6 : Test case 3: water-content profiles at $\mathrm{t}=5$ days. 


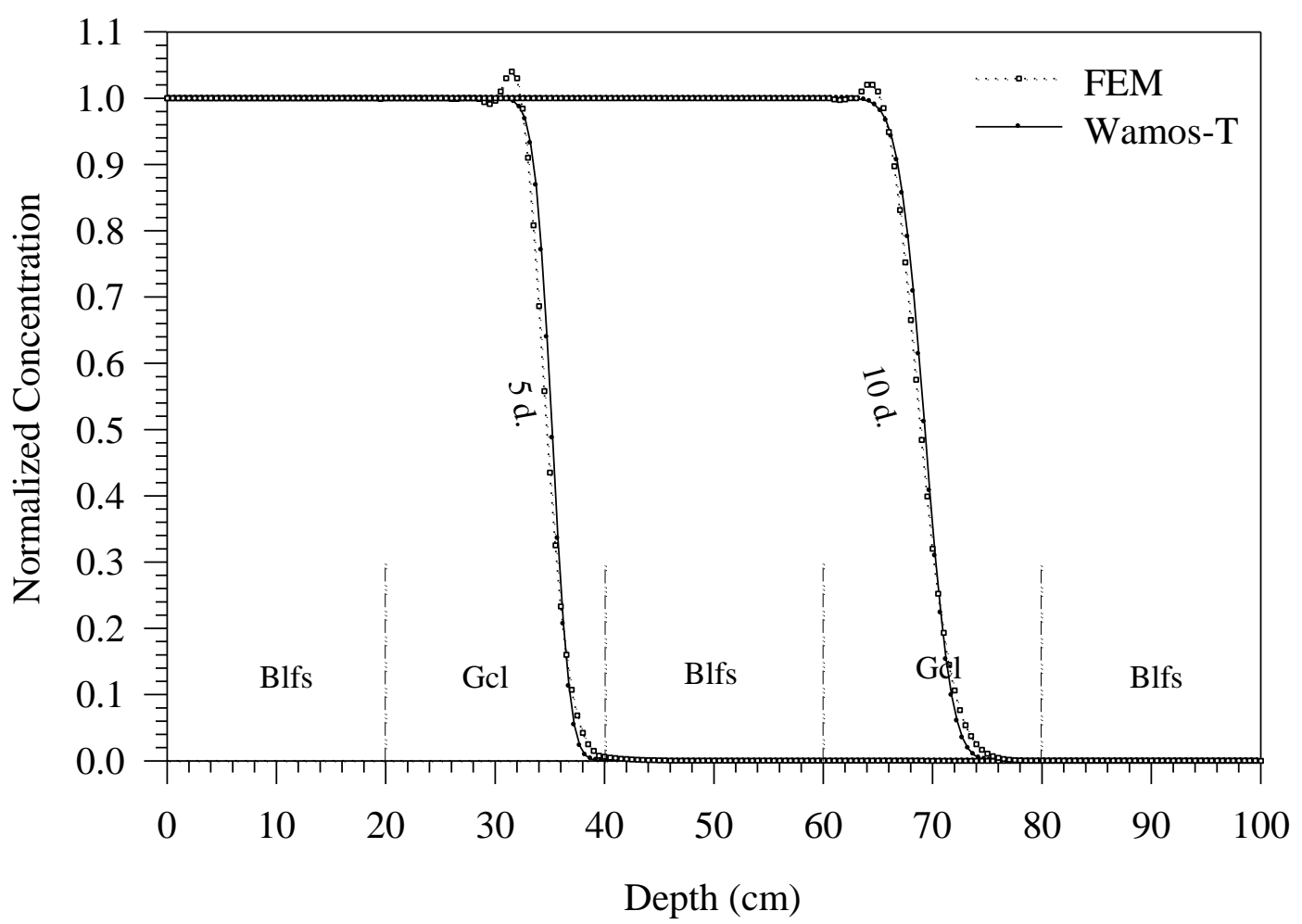

Figure 7 : Test case 3: normalized concentration profile after 5 and 10 days with $\mathrm{Pe}=10$.

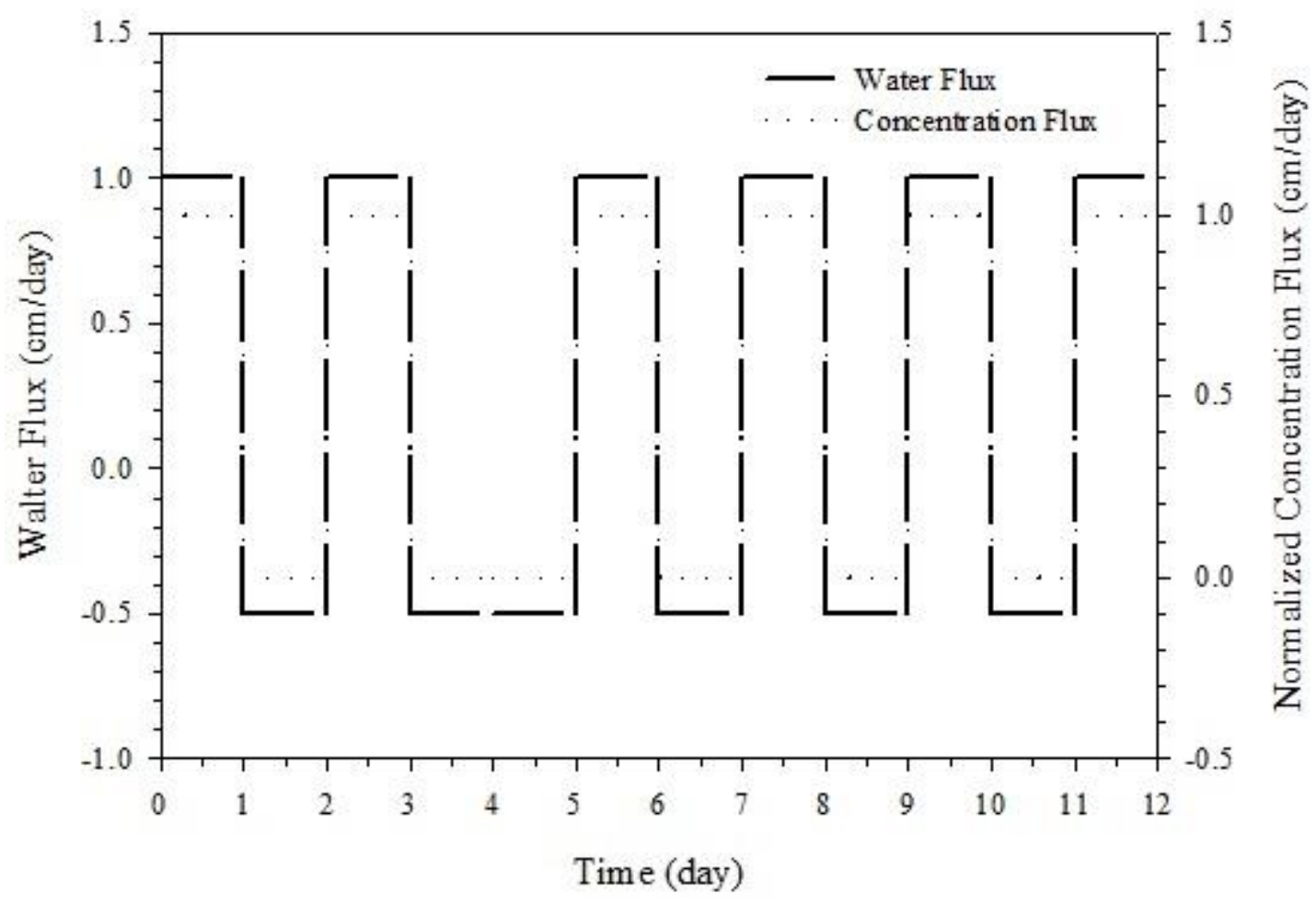

Figure 8 : Test case 4: boundary conditions at the top of the profile. 


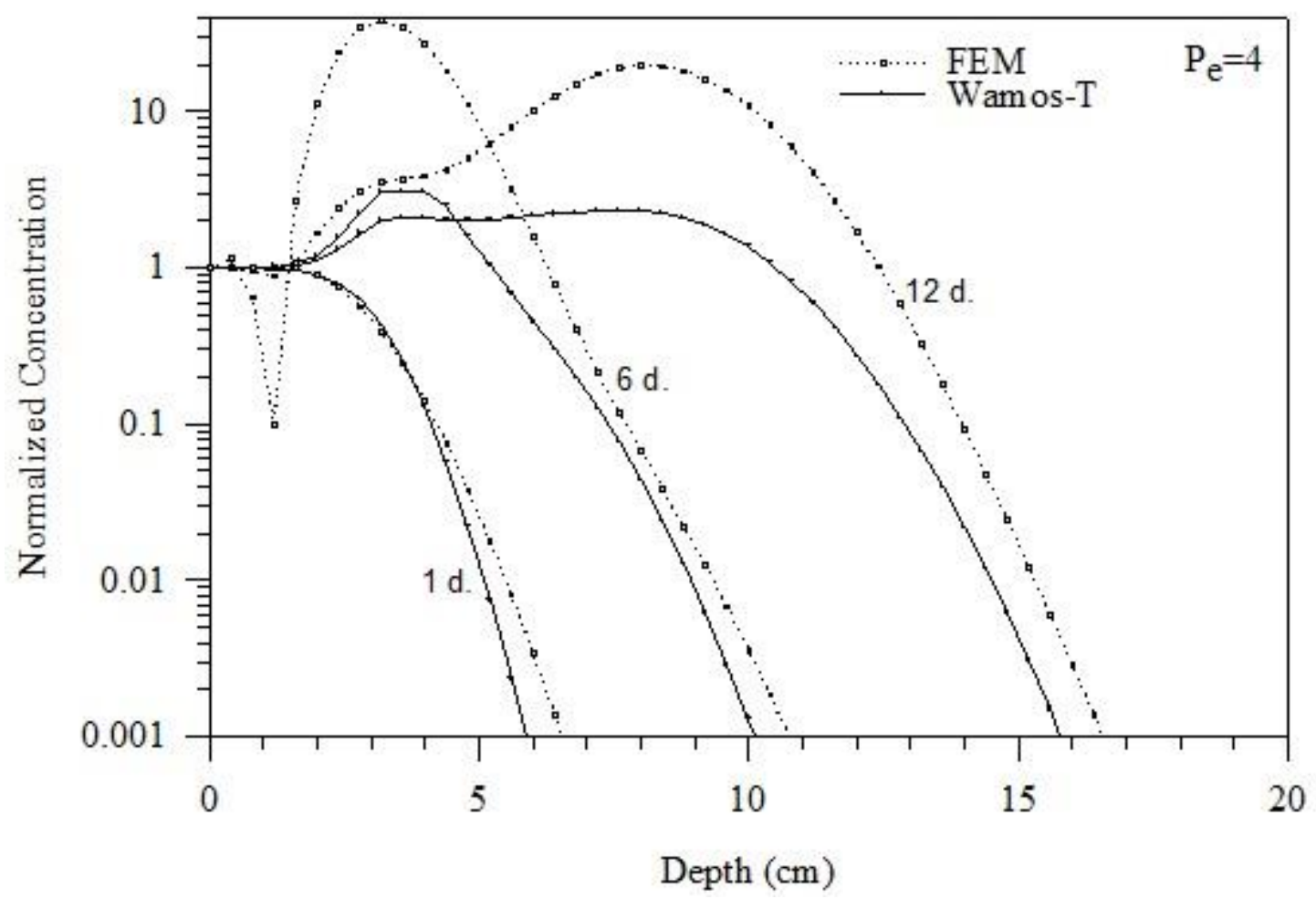

Figure 9 : Test case 4: normalized concentration profile after 1,6 and 12 days with $\Delta \mathrm{z}=0.4 \mathrm{~cm}$.

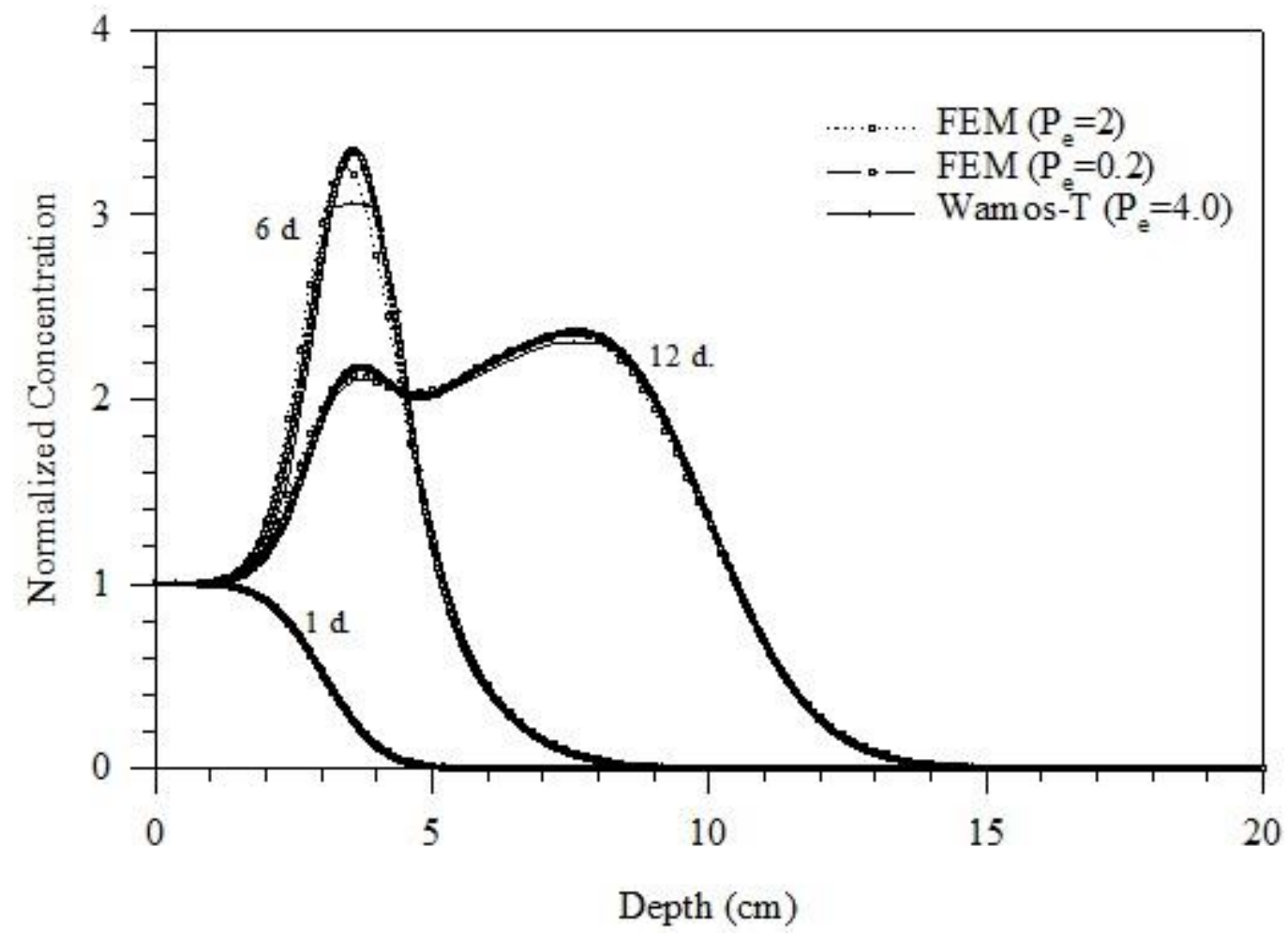

Figure 10 : Test case 4: normalized concentration profile after 1,6 and 12 days with $\Delta \mathrm{z}=0.2 \mathrm{~cm}$ and $\Delta \mathrm{z}=0.02 \mathrm{~cm}$ for FEM and $\Delta \mathrm{z}=0.4 \mathrm{~cm}$ for Wamos-T. 